\title{
PERAN STAKEHOLDER DALAM PEMBANGUNAN PARIWISATA DI PULAU SAMOSIR
}

\author{
Feronica Simanjorang ${ }^{1}$, Luchman Hakim ${ }^{2}$, Sunarti ${ }^{3}$ \\ Fakultas Ilmu Administrasi, Universitas Brawijaya, Malang, Indonesia ${ }^{13}$ \\ Fakultas Matematika Dan Ilmu Pengetahuan Alam, Universitas Brawijaya, Malang, Indonesia ${ }^{2}$ \\ Email: feronica.simanjorang@yahoo.com¹, lufehakim@yahoo.com² ${ }^{2}$ Sunarti@ub.ac.id ${ }^{3}$
}

\begin{abstract}
Samosir Island is known as the tourism center of Lake Toba Region that is managed based on DMO concept in 2010-2015. This study aims to identify the profile and tourism attractiveness of Samosir Island, and toidentify and analyze the role of stakeholders through DMO. The researcher used descriptive methods, and used primary and secondary data collected by observation, interview and documentation techniques. The results showed that most of the tourism activities on Samosir Island are related to Batak culture so that local community has an important role in maintaining the sustainability of attractions. There has not been found any good cooperation relations between the government, local communities, and the private sector in the development of Samosir Island tourism. Local communities choose to manage resources especially cultural sites independently. Similar conditions are also found in the private sector where business activities have not been running wuth an appropriate management strategy. Lack of continous control by the local government causes a decrease in the quality of service providers related attractions, amenities, and accessibility.
\end{abstract}

Keywords: stakeholders, Lake Toba, DMO, destination development

\begin{abstract}
ABSTRAK
Pulau Samosir dikenal sebagai sentra pariwisata Kawasan Danau Toba yang dikelola berdasarkan konsep DMO 2010-2015. Penelitian ini bertujuan untuk mengetahui profil daya tarik pariwisata Pulau Samosir, serta melakukan identifikasi dan analisis peran stakeholder melalui kehadiran DMO. Peneliti menggunakan metode deskriptif dengan pendekatan kualitatif, serta menggunakan data primer dan sekunder yang dikumpulkan dengan teknik observasi, wawancara dan dokumentasi. Hasil penelitian menunjukkan bahwa sebagian besar aktivitas pariwisata di Pulau Samosir berhubungan dengan budaya suku Batak sehingga masyarakat lokal memiliki peran penting dalam mempertahankan keberlanjutan atraksi. Peneliti belum menemukan adanya hubungan kerja sama yang kuat diantara pemerintah, masyarakat lokal, dan swasta dalam membangun pariwisata Pulau Samosir. Masyarakat lokal memilih untuk mengelola sumber daya pariwisata khususnya situs budaya secara mandiri. Kondisi yang sama juga ditemui dalam sektor pariwisata dimana aktivitas bisnis masih belum berjalan dengan strategi pengelolaan yang tepat. Kurangnya pengawasan yang berkelanjutan dari pemerintah daerah menyebabkan adanya penurunan kualitas dari para penyedia jasa baik yang berhubungan dengan atraksi, amenitas, maupun aksesibilitas.
\end{abstract}

Keywords: stakeholders, Lake Toba, DMO, destination development 


\section{PENDAHULUAN}

Pariwisata dianggap sebagai salah satu sektor ekspor yang disukai oleh banyak negaranegara berkembang. Brohman (1996) dan Khan et al. (1990) menyatakan jika pariwisata adalah sektor yang tidak perlu mengirim produk keluar negeri (invisible export) namun mampu menghasilkan multiplier effect bagi suatu negara. Oleh sebab itu, mengetahui motivasi wisatawan (push and pull motivations) dapat membantu pihak pengelola dalam membangun destinasi pariwisata. Yoeti (1996), Baloglu \& Uysal (1996), dan Haywood (2005) menyebutkan jika komponenkomponen seperti keragaman atraksi, amenitas, dan aksesibilitas disebut sebagai pull motivations yang bersifat tangible sedangkan push motivations cenderung bersifat intangible seperti keinginan untuk bepergian, kesehatan, budaya, sejarah, dan agama.

Sebagai suatu industry, pariwisata terhubung dengan banyak sektor dan stakeholder dari beragam latar belakang kepentingan. Pitana \& Gayatri (2005) menyatakan jika ada tiga stakeholder utama yang dianggap berperan penting dalam pengembangan destinasi pariwisata, yaitu pemerintah, pelaku usaha/swasta, dan masyarakat. Dalam penelitian Smaranda \& Daniela (2012) serta Beritelli et al. (2007) dinyatakan bahwa kolaborasi ketiga stakeholder diyakini mampu menciptakan sistem pengelolaan yang efektif serta mewujudkan pariwisata yang berkelanjutan. Hal tersebut kemudian melatarbelakangi terciptanya kelembagaan pariwisata.

$$
\text { Destination }
$$

Management

Organization (DMO) adalah kelembagaan pariwisata yang dipercaya mengelola dan mengembangkan destinasi wisata prioritas di Indonesia. Varghese dan Paul (2014) menyatakan jika DMO bersentuhan langsung dengan beberapa faktor seperti tata kelola, manajemen stakeholder, dan pengembangan infrastruktur yang akan mengarah pada peningkatan standar kualitas layanan dan produk. Dalam pelaksanannya di Indonesia, Abdurahman (2014) dan Adriani (2015) menyatakan jika DMO menerapkan pendekatan bottom-up dengan prinsip partisipatif, yaitu pelibatan stakeholder seluas- luasnya dalam satu kelompok kerja lokal atau Local Working Group (LWG) sebagai pintu masuk dalam membangun kesadaran stakeholder.

Salah satu destinasi yang menjadi pilot project kelembagaan DMO di Indonesia adalah Danau Toba yang memiliki Pulau Samosir sebagai destinasi pariwisata unggulan. Lokasinya yang berada di tengah Danau Toba dengan dengan latar Pegunungan Bukit Barisan menciptakan kesan visual yang indah. Potensi wisata terbesar yang dimiliki Pulau Samosir adalah wisata alam dan budaya.

Wardani \& Nasution (2016) mengungkapkan jika banyak desa di Pulau Samosir yang mengandalkan pariwisata sebagai tulang punggung pendapatan daerah. Beberapa di antaranya adalah Desa Tuktuk yang menampilkan proses pemahatan patung khas Batak, Desa Ambarita dengan Rumah Gorga dan kursi parsidangan Raja Siallagan, dan Desa Tomok yang menampilkan tarian Sigale-gale. Beragamnya pilihan atraksi wisata yang ada di Pulau Samosir sejalan dengan peningkatan jumlah kunjungan wisatawan yang pada tahun 2017 mencapai 278.059 orang atau meningkat sekitar $45,79 \%$ Dinas Pariwisata Kabupaten Samosir (2018).

Secara umum, atraksi wisata yang ada di Pulau Samosir masih dikelola secara tradisional atau kekeluargaan khususnya wisata budaya. Hal tersebut dikarenakan situssitus budaya yang ada merupakan milik keluarga/warisan. Andriani et al. (2019) menyatakan jika pihak pengelola destinasi di Pulau Samosir cenderung kurang terbuka untuk bekerja sama dengan pemerintah daerah. Kondisi tersebut menyebabkan penurunan dalam berinovasi karena pengelolaannya bersifat statis.

Kehadiran DMO menjadi peluang bagi stakeholder pariwisata di Pulau Samosir untuk saling terkoordinasi dalam satu kelembagaan pariwisata. Oleh sebab itu, peneliti tertarik untuk mengidentifikasi dan menganalisis pembangunan pariwisata Pulau Samosir melalui kelembagaan DMO Danau Toba 20102015, serta mengidentifikasi peran stakeholder yang meliputi masyarakat, pemerintah, dan swasta. 
KAJIAN PUSTAKA

\section{Pembangunan Pariwisata}

Spillane (1991) mengartikan pariwisata sebagai perjalanan dari suatu tempat ke tempat lain yang bersifat sementara, baik yang dilakukan perorangan maupun kelompok. Mereka yang melakukan aktivitas perjalanan disebut wisatawan sedangkan tempat yang dituju disebut destinasi pariwisata. Ketika aktivitas tersebut didukung oleh fasilitas layanan yang disediakan oleh pihak lain (industri pariwisata, masyarakat dan pemerintah) maka disebut dengan pariwisata (Ardika, 2014).

Pariwisata disebut sebagai bagian dari pembangunan daerah. Banyak sektor yang terlibat dalam pembangunan pariwisata seperti pertanian, perkebunan, perikanan dan kelautan, industri kecil, dan lain sebagainya. Semakin banyak sektor yang terlibat maka semakin banyak pula stakeholder dari beragam profesi dan kepentingan yang terlibat. Hal tersebut menjadi salah satu alasan rumitnya pembangunan dan pengelolaan pariwisata. Disisi lain, Suwantoro (2004) menyatakan jika banyak negara yang memilih pariwisata sebagai sector andalan dalam pembangunan ekonomi karena keberadaannya yang tidak begitu terpengaruh oleh gejolak ekonomi dunia

Selama wisatawan melakukan aktivitas wisata, kebutuhan seperti akomodasi, makanan, minuman, dan pelayanan informasi disebut sebagai produk wisata (Yoeti, 2013). Produk wisata menjadi dasar pengembangan komponen pariwisata, antara lain:

\section{Atraksi}

Cooper et al. (1993) mendefenisikan atraksi sebagai daya tarik yang berhubungan dengan lingkungan alam, budaya, seni pertunjukkan, dan keunikan daerah lainnya. Daya tarik tersebut kemudian diungkapkan Gunn (1988) dan Camilleri (2018) sebagai alasan bagi wisatawan untuk melakukan perjalanan. Oleh sebab itu, atraksi memerlukan pengelolaan dan pengambangan untuk tujuan jangka panjang. Hu \& Wall (2005) dalam penelitiannya menyampaikan jika tujuan utama pengembangan atraksi adalah meningkatkan jumlah kunjungan wisatawan.

2. Amenitas

Yoeti (1996) mendefenisikan amenitas sebagai kelengkapan dasar fisik yang berhubungan dengan ketersediaan akomodasi hotel, restoran, air bersih, akses komunikasi, dan sebagainya

3. Aksesibilitas

Segala jenis sarana dan prasarana transportasi yang mendukung pergerakan wisatawan dalam kaitannya dengan motivasi kunjungan wisata.

\section{Stakeholder Pariwisata}

Freeman (1984) dan Murphy \& Murphy (2004) menyatakan jika stakeholder adalah mereka yang memiliki kekuasan dan hak untuk berpartisipasi dalam pengambilan keputusan, serta mereka yang memberi dan/atau terkena dampak atas hasil keputusan tersebut. Mereka bisa laki-laki atau perempuan, komunitas, kelompok sosial, atau lembaga. Pitana \& Gayatri (2005) mengelompokkan stakeholder sebagai pemerintah, pelaku usaha/swasta, dan masyarakat karena mereka memiliki peran dan fungsi yang berbeda. Oleh sebab itu, penting untuk memahami peran dan tanggung jawab stakeholder agar pembangunan pariwisata dapat terwujud dan terlaksana dengan baik.

Pemerintah memiliki kewenangan dalam membuat regulasi yang bersifat mengikat. Kondisi tersebut ditujukan untuk menjamin para stakeholder berperilaku dalam koridor kebijakan yang telah ditetapkan (Pitana \& Diarta, 2009). Disisi lain, Hertifah (2003) mengungkapkan jika swasta berperan sebagai pelaku bisnis yang memiliki peluang dalam menciptakan lapangan pekerjaan. Masyarakat dengan berbagai sumber daya yang mereka miliki berperan sebagai host serta menciptakan lingkungan yang kondusif bagi wisatawan (Rahim, 2012).

\section{Destination Management Organization (DMO)}

DMO adalah sebuah konsep tata kelola pariwisata yang diwujudkan dalam satu kelembagaan pariwisata. Dalam penerapannya di Indonesia. Rahim (2010) mendefenisikan DMO sebagai sistem tata kelola yang terstruktur dan sinergis yang diyakini mampu mengkoordinasikan semua elemen destinasi, 
yaitu atraksi, amenitas, aksesibilitas dan sumber daya manusia. Peran DMO erat hubungannya dengan penerapan fungsi-fungsi manajemen. Varghese \& Paul (2014) dalam penelitiannya menegaskan bahwa DMO bersentuhan langsung dengan tata kelola, kontrol kualitas, manajemen stakeholder, pengembangan infrastruktur hingga mengarah pada standar kualitas layanan dan produk.

DMO memerlukan dukungan stakeholder untuk mewujudkan pembangunan pariwisata suatu destinasi pariwisata. Suharto (2011) menyatakan jika dalam memperkuat identitas kedaerahan, DMO memerlukan dukungan masyarakat lokal untuk menggali nilai kearifan lokal. Oleh sebab itu, dibutuhkan keterampilan manajemen yang kompleks untuk mendorong keterlibatan stakeholder.

Leakota (2015) dalam penelitiannya menegaskan pentingnya keterlibatan stakeholder dalam manajemen pariwisata. Tidak menyertakan salah satu dari perwakilan stakeholder dapat merusak upaya pengembangan pariwisata. Ketika kondisi tersebut dapat diwujudkan, Bornhorst et al. (2009) menyatakan jika DMO harus menjaga komunikasi yang positif antar stakeholder. Hal tersebut mencerminkan keberhasilan DMO dalam pembangunan pariwisata.

\section{METODE PENELITIAN}

Penelitian ini bersifat deskriptif dengan pendekatan kualitatif. Peneliti melakukan wawancara terhadap tujuh orang narasumber yang ditentukan dengan teknik snowball sampling. Untuk melengkapi data penelitian, data sekunder berupa dokumen, surat kabar, dan data statistic peneliti gunakan. Penelitian ini dianalisis menggunakan metode interaktif model Milles dan Huberman dengan empat tahapan, yaitu pengumpulan data, reduksi data, penyajian data dan penarikan kesimpulan. Keabsahan data dilakukan dengan triangulasi sumber.

Adapun fokus penelitian dalam penelitian ini adalah:

1. Mendeskripsikan pariwisata Pulau Samosir dari segi objek wisata.

2. Mengidentifikasi dan menganalisis pembangunan pariwisata yang dilakukan DMO di Pulau Samosir.
3. Mengidentifikasi peran stakeholder yang meliputi masyarakat, pemerintah, dan swasta

\section{HASIL DAN PEMBAHASAN}

\section{Destinasi Pariwisata di Pulau Samosir}

Dari berbagai sumber literatur, dapat dideskripsikan bahwa Pulau Samosir adalah pulau danau terbesar kelima di dunia yang keberadaannya menjadi bukti tinggalan letusan vulkanik Gunung Toba dimasa lampau (BPIW, 2018). Pulau Samosir berada di tengah Danau Toba dengan batas-batas wilayah, yaitu Kab. Karo dan Kab. Simalungun disebelah Utara; Kab. Toba Samosir di sebelah Timur; Kab. Tapanuli Utara dan Kab. Humbang Hasundutan di sebelah Selatan; dan Kab. Dairi di sebelah Barat.

Pulau Samosir dikenal sebagai sentra pariwisata Kawasan Danau Toba. Beragam objek wisata tersebar di Pulau Samosir yang mencakup atraksi alam dan budaya, beberapa diantaranya adalah:

1. Desa Tomok adalah pintu masuk Pulau Samosir yang dikenal dengan atraksi budaya berupa tari Sigale-gale. Pertunjukan Sigale-gale dimaknai sebagai pertunjukan wisata yang unik dan kaya akan nilai-nilai budaya suku Batak. Masyarakat mengemasnya dalam satu pertunjukan seni untuk menarik minat kunjungan wisatawan. Berdasarkan hasil pengamatan, pertunjukan tari Sigale-gale berjalan kurang kondusif. Pihak pengelola belum menerapkan sistem ticketing dan menentukan jadwal pertujukan tetap. Oleh sebab itu, wisatawan sering melewatkan pertunjukan pembuka atau baru bergabung dipertengahan acara. Pihak pengelola juga sudah menggunakan rekaman kaset dalam pertunjukkan tari Sigale-gale yang dulunya diiringi langsung oleh sekelompok orang yang memainkan alat musik tradisional. Hal tersebut tentunya mengurangi esensi dari pertunjukan seni yang seharusnya menampilkan kekayaan budaya lokal.

2. Desa Ambarita dikenal dengan objek wisata Batu Kursi Parsidangan Raja Siallagan yang menampilkan sejarah pemerintahan Raja Laga Siallagan di masa lampau. Batu kursi adalah tempat pertemuan raja dan para penasehat serta tokoh adat untuk menyelenggarakan persidangan (Siallagan, 
2011). Desa Ambarita awalnya dihuni oleh beberapa keluarga yang terikat dalam satu kerabat (marga). Oleh sebab itu, situs-situs budaya menjadi warisan keluarga. Di Desa Ambarita juga terdapat rumah adat Gorga yang sebagian besar sudah jarang dihuni oleh masyarakat lokal. Gorga dibangun dengan bergotong royong yang mencerminkan filosofi pedoman hidup dalam pergaulan antar individu. Ciri khas rumah Gorga adalah tidak memiliki sekat atau dinding pembatas yang memisahkan setiap bagian ruangan.

3. Desa Tuktuk Siadong menjadi tempat dimana wisatawan dapat belajar tentang seni pahat atau sekedar melihat desain ukiran khas Batak yang ada pada rumahrumah masyarakat lokal. Pengrajin lokal juga menjual hasil ukiran dalam bentuk pernak-pernik. Para wanita di desa ini juga dikenal dengan hasil kerajinan tenun Ulos dimana wisatawan juga dapat belajar atau membeli langsung dari para pengrajin.

4. Danau Sidihoni, dikenal dengan sebutan danau di atas danau karena Pulau Samosir berada di tengah-tengah Danau Toba. Akses masuk menuju Danau Sidihoni cukup baik meskipun jalan-jalan rusak dan berlubang masih sering ditemui.

5. Kawasan Kebun Raya Samosir, diisi oleh 260 jenis tanaman endemik seperti Pohon Pinus endemik, tumbuhan obat, tanaman hias, dan sebagainya. Saat ini pemerintah daerah tengah membangun akses jalan dari berbagai pintu masuk terdekat seperti dari Dermaga Feri Tomok.

Berdasarkan penjabaran di atas, diketahui bahwa sebagian besar objek wisata yang tersebar di Pulau Samosir bertema budaya. Hal tersebut erat kaitannya dengan sejarah orang Batak pertama yang diyakini menetap di Gunung Pusuk Buhit, Kab. Samosir (Malau, 1994). Oleh sebab itu, budaya suku Batak sangat dekat dengan kehidupan masyarakat di Pulau Samosir. Mereka memiliki peran penting dalam melestarikan situs-situs budaya dan menjaga keberlanjutan budaya.

\section{Pembangunan Pariwisata yang dilakukan DMO di Pulau Samosir}

Sebelum melaksanakan pembangunan pariwisata di Pulau Samosir, DMO terlebih dahulu memastikan stakeholder terlibat dalam setiap proses perencanaan, pelaksanaan, dan pengelolaan. Stakeholder yang terlibat mencakup:

1. Masyarakat lokal dan para pengelola destinasi

2. Pihak swasta seperti pemilik penginapan, pemilik kapal, pengusaha ikan dengan sistem keramba jarring apung (KJA)

3. Pemerintah daerah, yaitu Dinas Pariwisata, Dinas Perhubungan, dan Dinas Pekerjaan Umum.

Rahim (2010) menyatakan jika para stakeholder dipertemukan dalam satu platform komunikasi untuk mengidentifikasi isu dan permasalahan berdasarkan kondisi aktual. Sebagai destinasi pariwisata dengan latar belakang budaya yang kuat, maka pola musyawarah dalam pengambilan keputusan bukanlah hal asing. Oleh sebab itu, aktivitas DMO di Pulau Samosir selalu didasarkan pada hasil kesepakatan stakeholder.

DMO juga menerapkan pendekatan bottom-up untuk memahami nilai-nilai budaya agar selaras dengan kebijakan pemerintah daerah. Hal tersebut ditujukan agar tercipta hubungan yang harmonis antara masyarakat lokal, wisatawan, dan industry pariwisata. Dalam penelitian Zhang et al. (2006) dan Bornhorst et al. (2009) dinyatakan jika keberhasilan pembangunan pariwisata dapat terlihat dari hubungan antar stakeholder yang tercermin melalui komunikasi positif.

Di Desa Ambarita, DMO melihat peluang untuk memanfaatkan rumah adat Gorga sebagai homestay. Peluang tersebut dimanfaatkan untuk memenuhi kebutuhan akomodasi sekaligus meminimalisir pembangunan fisik. Diketahui bahwa ketersediaan akomodasi seperti homestay, hostel, dan cottage, berpusat di Desa Tuktuk. Dinas Pariwisata Kab. Samosir (2018) mencatat ada sekitar 1.453 penginapan kelas melati yang tersebar di Pulau Samosir yang sebagian besar berpusat di Tuktuk Siadong.

Perencanaan tersebut menjadi bentuk inovasi yang diharapkan dapat mendorong aktivitas wisata di Desa Ambarita sekaligus merangsang pertumbuhan ekonomi. Ketika disampaikan kepada masyarakat lokal, DMO 
mendapatkan penolakan. Disisi lain, aktivitas seperti pelatihan hospitality dan kepemanduan disambut baik oleh masyarakat lokal. Mereka secara aktif berpartisipasi dalam setiap kegiatan dan bersedia menjadi pemandu wisata. Batu Parsidangan yang menjadi objek wisata di Desa Ambarita wisatawan membutuhkan kehadiran pemandu wisata untuk menginterpretasikan makna dan latar belakang situs-situs warisan. Hal yang sama diungkapkan Huang \& Chan (2010) serta Barrow (2013) yang menyatakan jika kehadiran seorang pemandu wisata profesional dapat membantu pengembangan dan pengelolaan pariwisata. Mereka memiliki kapabilitas dalam berkomunikasi dan menginterpretasikan objek wisata dengan baik.

Kondisi yang bertolak belakang tersebut, diketahui sebagai hasil dari rendahnya tingkat kepercayaan masyarakat terhadap kinerja pemerintah. Oleh sebab itu, masyarakat menyakini bahwa mereka mampu mengelola situs budaya yang ada secara mandiri. Masyarakat juga meyakini jika situs budaya di lingkungan tempat mereka tinggal adalah warisan keluarga sehingga menyebabkan kecenderungan untuk menolak intervensi pihak luar.

Penolakan atas pengelolaan atraksi budaya juga terjadi di Desa Tomok yang dikenal dengan pertunjukkan tari Sigale-gale. Pihak pengelola diketahui belum terbuka dengan DMO yang ingin mengelola dan melakukan perbaikan khususnya dalam hal pelayanan. Mereka menyadari jika pertunjukan Sigale-gale memberikan dampak ekonomi langsung bagi masyarakat lokal sehingga cenderung menolak kerjasama yang ditawarkan oleh pemerintah daerah. Hal yang serupa juga diungkapkan Andriani et al. (2019) yang menyatakan bahwa terjadi penurunan kualitas tampilan dari pertunjukan tari Sigale-gale namun pihak pengelola justru belum ingin bekerjasama dengan Dinas Pariwisata meskipun mereka menyadari perlunya bantuan khususnya dalam hal anggaran.

Berdasarkan penjabaran di atas diketahui bahwa masyarakat lokal belum sepenuhnya memahami bahwa keberadaan DMO bukan untuk menggantikan konsep pengelolaan yang sudah ada melainkan memperkuat pola manajemen yang ada. Dalam studi Alexsandrov (2014) disebutkan bahwa DMO harus memiliki tujuan untuk memberi manfaat ekonomi bagi masyarakat lokal dan meminimalisir dampak negative dari segi sosial. Oleh sebab itu, Leakota (2015) menyarankan agar masyarakat lokal masuk dalam struktur manajemen pariwisata.

Disamping isu dan permasalahan terkait pengelolaan situs-situs budaya, DMO juga dihadapkan pada isu kerusakan lingkungan. Ekawati (2016) menyatakan bahwa ada 262 ton sampah per hari yang masuk ke Danau Toba dimana budidaya KJA, limbah perusahaan dan rumah tangga turut menyumbang pencemaran air di Danau Toba. Dalam hal tersebut, pihak swasta selaku pemilik KJA terbesar berkontribusi besar dalam penurunan kualitas air danau. Ada sekitar 11.781 unit KJA milik PT. Aquafarm, PT. Sari Tani Pemika, dan masyarakat yang menjadi penyumbang limbah terbesar yang mendorong penurunan kualitas air Danau Toba.

Budidaya KJA yang telah lama dilakukan di perairan danau diperkirakan sudah melampaui daya dukung lingkungannya. Danau Toba yang seakan berubah fungsi menjadi tempat pembuangan limbah oleh masyarakat, swasta, bahkan pemerintah setempat. Kondisi tersebut juga diungkapkan Pardede (2016) yang menyatakan jika rendahnya apresiasi stakeholder terhadap kebersihan lingkungan menjadi bukti lemahnya kualitas SDM.

Menyikapi kondisi tersebut, pemerintah dengan kewenangannya sebagai regulator mengeluarkan regulasi yang mengatur tentang pemanfaatan Kawasan Danau Toba dan sekitarnya pada tahun 2014. Salah satu langkah yang dilakukan pemerintah adalah dengan melarang keberadaan KJA dan kemudian mendorong peralihan mata pencarian dengan memberikan pelatihan, yakni mengelola tanaman eceng gondok sebagai souvenir yang menarik bagi wisatawan. Implementasi perencanaan tersebut tentunya memerlukan penyesuaian agar paradigma yang telah terbentuk mampu bergeser menuju 
pariwisata yang berkelanjutan baik dari aspek sosial, ekonomi maupun lingkungan.

\section{- Perbaikan Aksesibilitas di Pulau Samosir}

Untuk tiba di Pulau Samosir hanya ada dua sarana yang mendukung wisatawan yaitu transportasi danau dan darat. Satu-satunya akses darat mengharuskan wisatawan menempuh perjalanan sepanjang $121 \mathrm{~km}$ melalui Kab. Toba Samosir. Kondisi jalan menuju Pulau Samosir diketahui berstatus 'sedang' yakni jalan aspal dalam kondisi rusak ringan $(8 \leq \mathrm{IRI} \leq 12)$. Dalam upaya perbaikan, diperlukan kerjasama dari pemerintah daerah sekitar, namun perbedaan kebijakan antar daerah menyebabkan prosesnya belum berjalan dengan baik. Hal tersebut juga disampaikan Currie dan Falconer (2014) dalam penelitiannya yang menyatakan jika sarana dan prasarana transportasi adalah elemen yang saling bergantung sehingga diperlukan kerja sama antar pihak dilingkungan pemerintah.

Menyadari kebutuhan akan dukungan lintas sektor dan daerah maka kewenangan atas pembangunan dan perbaikan infrastruktur jalan sekawasan Danau Toba kembali diintegrasikan kepada Kementerian Pekerjaan Umum dan Perumahan Rakyat (PUPR). Berdasarkan data yang diperoleh dari Dinas Pekerjaan Umum (PU) Kab. Samosir tahun 2017 terdapat jalan sepanjang 959,21 km yang menghubungkan wisatawan ke Pulau Samosir, dimana 265,06 km diantaranya dengan kondisi baik dan sisanya dalam kondisi sedang $(82,29$ $\mathrm{km})$, rusak $(153,92 \mathrm{~km})$ dan rusak berat $(259,94 \mathrm{~km})$.

Selain menggunakan jalur darat, wisatawan juga dapat memilih transportasi air seperti kapal ferry atau kapal bermotor yang akan mengantarkan wisatawan langsung ke Pulau Samosir melalui lima dermaga penyeberangan yang ada di tiga kabupaten utama. Umumnya kondisi dermaga masih sangat tradisional sehingga kurang memperhatikan kenyamanan serta keselamatan penumpang. Seringkali penumpang harus menaiki tangga kayu tanpa pegangan, disisi lain fasilitas penunjang yang ada di dalam kapal khususnya kapal bermotor seperti life jacket, pelampung, sekoci, perlengkapan komunikasi dan aturan mengenai batasan jumlah penumpang belum diterapkan dengan benar. Kecelakaan kapal motor Sinar Bangun pada tahun 2018 menjadi bukti kurangnya pengawasan dalam menjalankan dan menyediakan fasilitas keselamatan pada transportasi air di Kawasan Danau Toba. Setelah kejadian tersebut, pemerintah pusat baru memulai pengarahan tentang perbaikan sistem manajemen transportasi dengan melimpahkan kekuasaan pada PT. Angkutan Sungai, Danau, dan Penyeberangan Indonesia Ferry (ASDP).

\section{Peran Stakeholder dalam Pembangunan Pariwisata di Pulau Samosir}

Berdasarkan penjabaran di atas, maka dapat diuraikan peran stakeholder dalam pembangunan pariwisata di Pulau Samosir, antara lain:

1. Pemerintah daerah:

- Pembinaan sumber daya manusia melalui berbagai pelatihan seperti hospitality, kepemanduan, dan pelatihan keterampilan pembuatan souvenir.

- Perbaikan aksesibilitas, melimpahkan kewenangan terkait sistem manajemen transportasi danau air kepada BUMN yaitu PT. ASDP, dan kepada Kementerian PUPR terkait perbaikan dan pembangunan jalan.

2. Swasta

- Pengusaha transportasi, menyediakan transportasi air seperti kapal motor untuk mendukung aksesibilitas wisatawan menuju Pulau Samosir.

Penyedia akomodasi penginapan

3. Masyarakat

- Mengelola sebagian besar atraksi budaya yang ada di Pulau Samosir.

- Menjadi pemandu wisata khususnya pada situs-situs budaya yang memiliki latar belakang sejarah.

\section{KESIMPULAN DAN SARAN \\ Kesimpulan}

Dalam pembangunan pariwisata, stakeholder memiliki peran dan tanggung jawab yang berbeda. Berdasarkan hasil penelitian dapat disimpulkan bahwa:

1. Masyarakat lokal berperan penting dalam mempertahankan warisan budaya melalui 
pertunjukan seri. Mereka meyakini mampu mengelola warisan dan situs-situs budaya secara mandiri. Masyarakat menempatkan dirinya sebagai subjek yang berhak untuk mengelola sumber daya pariwisata. Hasilnya, masyarakat secara langsung menerima manfaat ekonomi dari aktivitas wisata yang terjadi dilingkungan mereka. Disisi lain, kondisi tersebut menghambat pemerintah untuk membangun hubungan kerja sama sehingga sulit melakukan inovasi.

2. Pemerintah daerah diketahui aktif memberikan pelatihan keterampilan untuk meningkatkan kapasitas SDM di desa-desa wisata unggulan. Hal tersebut disambut baik oleh masyarakat lokal dengan cara berpartisipasi, namun disisi lain peneliti belum melihat adanya pengawasan yang berkelanjutan sehingga kegiatannya masih dalam bentuk program. Dalam upaya perbaikan sarana dan prasarana aksesibilitas, Kementerian PUPR diketahui terus memberikan dukungan sehingga pelaksanaannya berjalan dengan baik.

3. Pihak swasta diketahui belum menjalin kerja sama dengan pemerintah. Mereka berperan dalam menyediakan sarana transportasi danau dan akomodasi penginapan, namun hal tersebut belum terhubungan dengan aktivitas wisata lainnya.

\section{Saran}

Berdasarkan hasil penelitian, maka saran yang dapat diberikan peneliti adalah:

\section{Dinas Pariwisata}

1. Memaksimalkan koordinasi antar stakeholder baik dilingkungan pemerintahan maupun masyarakat dan swasta (vertikal dan horizontal).

2. Melakukan pengawasan dan evaluasi terhadap sektor perikanan yang diketahui membahayakan wilayah perairan danau dengan aktivitas budidaya ikan sistem KJA.

\section{Swasta}

1. Menerapkan standarisasi pelayanan khususnya dalam transportasi air terkait kenyamanan dan keamanan wisatawan.

2. Menjalin kerjasama dengan pemerintah bersama-sama dengan masyarakat terkait usaha budidaya ikan dengan sistem KJA untuk meminimalisir dampak negatif yang mempengaruhi keberlanjutan SDA.

\section{Masyarakat}

1. Perlunya kesadaran untuk bekerja sama dengan pemerintah dalam mengelola situs budaya demi mempertahankan kualitas dan keberlanjutan destinasi pariwisata.

2. Meningkatkan kepedulian akan peran dan tanggung jawab sebagai host sekaligus pelaku wisata dalam menciptakan lingkungan yang layak bagi aktivitas wisata.

\section{DAFTAR PUSTAKA}

Abdurahman, B. (2014). Destination Management Organization in Flores. Jurnal Kepariwisataan Indonesia, 9.

Aleksandrov, K. (2012). The Role of DMO for Sustainable Development of a Tourist Destination - Bulgaria Case. In L. Dimitris (Ed.), Journal of Tourism Research (Vol. 9, pp. 198-209). Tourism Research Institute.

Andriani, R., Brahmanto, E., Purba, C. C. S., Tari, V., Tari, V., \& Meningkatkan, S. D. (2013). Value Tari Sigale-Gale Dalam Meningkatkan Wisata Budaya Desa Tomok Kabupaten Samosir. (1), 25-35.

Adriani, Y. (2015). Pengembangan Kelembagaan DMO. Tanjungpandan.

Ardika, I. G. (2014). Peran Strategik DMO Dalam Penyelenggaraan Kepariwisataan Indonesia. Jakarta.

Baloglu, S., \& Uysal, M. (1996). Market segments of push and pull motivations: a canonical correlation approach. International Journal of Contemporary Hospitality Management, 8(3), 32-38.

Barrow, G. C. (2013). Interpretation planning and its role in sustainable tourism and visitor management at geoheritage sites. International Journal of Geoheritage, 1(1), 30-38. 
Beritelli, P., Buffa, F., \& Martini, U. (2015). The coordinating DMO or coordinators in the DMO? - an alternative perspective with the help of network analysis. Tourism Review, 70(1), 24-42. https://doi.org/10.1108/TR-04-20140018

Bornhorst, T., Brent Ritchie, J. R., \& Sheehan, L. (2010). Determinants of tourism success for DMOs \& destinations: An empirical examination of stakeholders' perspectives. Tourism Management, 31(5), 572-589. https://doi.org/10.1016/j.tourman.2009.0 6.008

BPIW. (2018). Dokumen Profil Pengembangan Kawasan Strategis Resume Kawasan Danau Toba. Retrieved from http://bpiw.pu.go.id/product/get_index/

Brohman, J. (1996). New directions in tourism for Third World development. Annals of Tourism Research, 23(1), 48-70. https://doi.org/10.1016/01607383(95)00043-7

Camilleri, M. (2018). Travel Marketing, Tourism Economics and The Airline Product an Introduction to Theory and Practice. Switzerland. Springer Nature.

Currie, C., \& Falconer, P. (2014). Maintaining sustainable island destinations in Scotland: The role of the transporttourism relationship. Journal of Destination Marketing and Management, 3(3), $162-172$. https://doi.org/10.1016/j.jdmm.2013.10. $\underline{005}$

Cooper, C., Fletcher, J., Gilbert, D., \& Wanhill, S. (1993). An Introduction to Tourism. Tourism Principles and Practice, 7-12.

Ekawati, S., Supriyanto, B., Panjaitan, J. H., \& Mulyadi, Y. (2016). Mendorong Pengembangan Danau Toba Sebagai Destinasi Pariwisata Prioritas. Policy Brief, 10(8), 1-4.
Freeman, E. (1984). Strategic Management: a Stakeholder Approach. Boston: Pitman.

Gunn, C. (1998). Vacationscape: The Design of Travel Environments. New York: Van Nostrand Reinhold Company.

Haywood, M. (2005). Economic Business Cycles and the Tourism Life-Cycle Concept. In K. Loannides, Dimitri; Debbage (Ed.), The Economic Geography of the Tourist Industry: a Supply-side Analysis (pp. 275-286). London: Routledge.

Huang, S., Hsu, C. H. C., \& Chan, A. (2010). Tour guide performance and tourist satisfaction: A study of the package tours in Shanghai. Journal of Hospitality and Tourism Research, 34(1), 3-33. https://doi.org/10.1177/10963480093498 $\underline{15}$

Hu, W., \& Wall, G. (2005). Environmental management, environmental image and the competitive tourist attraction. Journal of Sustainable Tourism, 13(6), 617-635. https://doi.org/10.1080/09669580508668 $\underline{584}$

Khan, H., Seng, C. F., \& Cheong, W. K. (1990). Tourism multiplier effects on Singapore. Annals of Tourism Research, 17(3), 408-418. https://doi.org/10.1016/01607383(90)90006-D

Leakota, L. (2015). The Importance of Rural Communities' Participation in the Management of Tourism Management: a Case Study from Lesotho. Worldwide Hospitality and Tourism Themes, (Unit 07), 453-462. Retrieved from http://dx.doi.org/10.1108/WHATT-062015-0029

Malau, G. (1994). Dolok Pusuk Buhit. Jakarta Timur: PT. Balai Pustaka.

Murphy, P., \& Murphy, A. (2004). Strategic Management for Tourism Communities: 
Brigding the Gaps. Canada: Cormwell Press.

Pardede, F. R. E. P., \& Suryawan, I. B. (2016). Strategi Pengelolaan Kabupaten Samosir Sebagai Daya Tarik Wisata Alam Di Provinsi Sumatera Utara. Jurnal Destinasi Pariwisata, 4(1), 14. https://doi.org/10.24843/jdepar.2016.v04 .i01.p03

Pitana, I G; Gayatri, P. G. (2005). Sosiologi Pariwisata. Yogyakarta: Andi.

Pitana, I. G., \& Diarta, I. K. (2009). Pengantar Ilmu Pariwisata. Yogyakarta: Andi.

Rahim, F. (2010). Pedoman Pembentukan dan Pengembangan Destination Management Organization (DMO). Jakarta: Kementerian Kebudayaan dan Pariwisata.

Rahim, F. (2012). Buku Pedoman Kelompok Sadar Wisata. Jakarta: Kementerian Kebudayaan dan Pariwisata.

Siallagan, A. (2011). Analisis Permintaan Wisatawan Nusantara Objek Wisata Batu Kursi Siallagan, Kecamatan Simanindo, Kabupaten Samosir. Universitas Diponegoro.

Smaranda, Simoni; Daniela, M. (2012). Tourism Organization and Coordination in Australia and the Managerial Strategy for Tourism Development. Journal of Knowledge Management, Economics and Information Technology, 2 (5), 1-10.

Spillane, J. (1991). Ekonomi Pariwisata, Sejarah dan Prospeknya. Yogyakarta: Kanisius.

Suharto, B. (2011). Tata Kelola Organisasi Destinasi Candi Borobudur. Jurnal Ekonomi Manajemen Sumber Daya, 12(1), 35-49.

Suwantoro, G. (2004). Dasar-dasar Pariwisata. Yogyakarta: Andi.
Varghese, B., Paul, J., \& Itty, N. (2014). a Literature Review on Destination Management Organization (DMO). Strategic Interventions of DMO in tourism View project Medical Tourism View project. Zenitt, International Journal of Multidisciplinary Research, 4(12), $82 \quad 88 . \quad$ Retrieved from https://www.researchgate.net/publication /269114247

Wardani, Mentari; Nasution, N. (2016). Kontribusi Pengembangan Pariwisata Danau Toba Melalui Skema BOP ( Badan Otorita Pariwisata) Bagi Masyarakat di Sekitar Danau Melalui Skema BOP.

Yoeti, O. (1996). Pengantar Ilmu Pariwisata. Bandung: Angkasa.

Yoeti, O. (2013). Pengantar Ilmu Pariwisata. Bandung: Angkasa.

Zhang, J., Inbakaran, R. J., \& Jackson, M. S. (2006). Understanding community attitudes towards tourism and host-guest interaction in the urban - Rural border region. Tourism Geographies, 8(2), 182204.

https://doi.org/10.1080/146166806005854 55 
